\title{
Some Observations on Schooling in Fish.
}

\author{
By
}

\author{
G. M. Spooner, B.A.,
}

Student Probationer at the Plymouth Laboratory.

With 12 Figures in the Text.

\section{CONTENTS}

Problems connected with Schooling . . . . . . . . 422

Bass as a subject for experiments on Schooling . . . . . . . 425

II. Description of Experiments ․ . . . . . . . . . . . . 426

Preliminary . . . . . . . . . . . . 426

Showing that sight is involved-Reactions of the fish to a mirror . . 431

Summary of experiments with a plain mirror . . . . . 433

A. Reactions of individual fish . . . . . . . . 433

B. General power of attraction of a mirror as determined by comparison of average positions of the fish . . . 437

The main attributes of that which induces a Schooling response $\quad . \quad$. 442

Reaction to mirrors used as a basis for further experiments . . . . 444

Reaction of fish to small areas of mirror . . . . 445

Reactions to a broken mirror surface . . . . . . . 445

iII. Application of Results to the Schooling Problem . . . . . 446

Summary . . . . . . . . . . . . . . . 447

\section{INTRODUCTION.}

The Schooling Habit.

THE habit among certain kinds of fish of living in herds, or "schools," is too familiar to require much in the way of introduction. Those fish in which the habit is most strongly developed, such as members of the herring and mackerel families, though scarcely developing such organisation as can be seen in some bird flocks, clearly display a considerable degree of mutual adjustment between individuals. The term "school " or "shoal" is applied to fish herds which are not mere chance aggregates brought together by the common attraction of some external condition (e.g. collections of salmon on migration up river) but definitely involve mutual reaction of one individual to another. 
Almost every stage can be found between regular school fish and those in which temporary bunching together may occur on certain occasions, as Parr (3) has pointed out, giving Gobius ruthensparii as an example of a simple case. "The adults of this species generally do not school at all, but when splashing among the algæ where they are scattered one may very commonly observe that they do not dart off in all directions, but converge to form a school of very short duration, spreading again after a short flight."* Other kinds form more stable, though not permanent, schools. As an example there is the European Stickleback (Gasterosteus aculeatus), " which will travel in rather perfectly formed schools but will scatter for breeding and feeding. Similar behaviour also seems to be found among the American killies (Fundulus) and many other fishes" (p. 29). The bass. (Morone labrax), in its immature stages, lives in considerable schools, but as it grows older becomes increasingly less sociable. During the shoaling period, however, the habit is not so dominant as to preclude considerable independent individual action, and has its main effect in keeping the group together, rather than in co-ordinating movements.

From such cases we pass to permanent school fish, such as members of the herring and mackerel families, in which the school is extremely stable and is not broken up unless there is violent disturbance. Since these fish are continually on the move, for feeding as well as travelling, their case differs from that of Gasterosteus aculeatus, etc., only in degree. The behaviour of individuals of these fish leaves an impression of being extremely stereotyped, and non-variable, and specialised in the development of actions suitable for the maintainance of the school. That these actions are developed to a degree of some refinement is apparent from the regularity and co-ordination of movement so characteristic of the schools. So, when the individual is considered, it may well be asked what are the nature of its actions that result in the school apparently working as a unity. Here is a subject for enquiry.

\section{Problems Connected with Schooling.}

The phenomenon of schooling has received surprisingly little attention. either from fishery investigators or from those studying animal behaviour. Parr (3), it would appear, has been the first to examine the subject in the light of cold reason, and to apply a form of scientific treatment to it. But the subject is here approached from a somewhat different aspect.

Setting ecological questions aside for the time being, and keeping an.

* The habit of packing together when scared is common among true schooling fish, as. has been observed in the case of mackerel kept in the aquarium, and is well known to occur when sprat, pilchard, etc., are attacked by sea birds. It is possible also that it. occurs among non-schooling fish such as hake (Bateson 1, p. 249). If so this is a case of: schooling in its most rudimentary form. 
analytical standpoint, the problems connected with schooling, whether permanent or temporary, well developed or indefinite, may be expressed as follows :-

1. Given the phenomenon of schooling.

(a) What sort of actions on the part of the individual are concerned in keeping the school together, and how can various activities displayed by the school be interpreted in terms of behaviour of single fish?

(b) What are the essential elements in the aspect of its surroundings to which the individual reacts, and which in general influence its behaviour ?

(c) From the special aspect of sense physiology, what are the senses concerned? How refined are these senses?

2. Given a fish liable to display schooling behaviour.

(a) Under what conditions will that behaviour be displayed?

(b) How determinate is that behaviour-to what degree of probability can it be predicted?

(c) To what degree of certainty can it be experimentally induced ?

(1) Questions $1(a)$ and (b) cannot strictly be separated from each other, being really only two ways of propounding the same problem. The one focuses attention on the animal's actions, the other on the surrounding conditions. But actions cannot be described without some sort of reference to environment, and the effect of the latter can only be stated in terms of actions being performed at the moment. Only in limiting cases does a clear distinction emerge; the first enquiry dealing with "reaetions," the second with "stimuli" producing them. And as for experimental purposes it is generally convenient to deal with clear-cut reactions, these two aspects of the phenomenon may be kept separate.

(1a) This is largely a matter of description, but observation should be made on whether the individual behaviour is variable or rigid, complicated or consisting of a limited set of more or less cut and dried reactions. Naturally, the more stable and mechanical the movement of the school, the more automatic the actions of the individual fish are likely to be. It is of interest to know how strongly developed and how permanent are the reactions involved; e.g. will a fish always react to a neighbour in a similar way whether forming part of a school or not? It is further to be noted how far external conditions influence the observed behaviour. For instance, when a school is feeding there are not such rigid adjustments between individuals as when it is travelling ordinarily ; in the former case like orientation of all the members of the school may completely disappear.

(1b) Here one is particularly concerned with such questions as " How do the fish recognise each other?" Or rather, "What distinctions do the 
fish draw between neighbouring fish and other objects ?" Or, put another way, "What are the essential elements in a situation which results in a schooling response?" In any case, however the question is framed, it is not intended that it should convey anything beyond an objective meaning. Experimentally a fish, which reacts in a definite way when another fish comes near it, is tested under various circumstances in which some factor in the normal situation is lacking. The features shared in common by those situations which produce the normal reaction may be considered as their essential elements. By this means evidence may be procured as to the importance of movement, form, general contrast, details, spatial relations, and so on. The extent of the data obtainable depends on the strength and persistency of the original reaction.

(1c) By treatment of the animal as a unit, it is possible to demonstrate empirically the dominant sense involved; and to deal with such questions as the following: "Assuming sight to be involved, at what distance (for given illumination and turbidity of water) will a fish exert attraction on another?" "How complete an image is necessary and what are the essential elements of it ?" "What illumination is necessary ?" Further, the degree of refinement of the sense may be tested with considerable accuracy by conditioning methods. But neither these nor other exact analytical methods of sense physiology are here utilised, and so further consideration of them is unnecessary.

(2) Once observation is undertaken on fish in the above connections, this second side of the problem is bound to open up. The answers given to the questions concerned can at best be approximations, and in any case only apply to specified laboratory conditions. As for elucidation of behaviour under natural circumstances, they cannot legitimately be used. except as evidence (often, however, this evidence, combined with that of what observation is possible in the field, is sufficient to give an adequate answer).

(2a) By this is implied not only what are the conditions under which fish maintain a school, but also what changes are necessary to convert a "non-schooling" state of the fish into a "schooling" state, and vice versa.

( $2 b$ and $c$ ) To deal with these questions fully would involve the whole subject of determinancy with respect to behaviour actions of animals. It is enough to record such observations as bear on the points. Empirical treatment is given to these questions not merely for the sake of cautious procedure, but because theoretical consideration leads round to this as the only permissible method. The questions are framed in a way which does not presuppose tropistic behaviour or indeed any causal relations whatever, but if actions exist that are sufficiently fixed to be conveniently 
termed "tropisms," they will appear during investigation. The habit of postulating hypothetical tropisms constant only in hypothetical ideal conditions (so that in practice they would be partially obscured by secondary influences) is considered a fallacious method of treatment.

In this paper an account is given of certain observations on the bass (Morone labrax L.). These are discussed in their bearing on the problems outlined above in so far as they concern that species.

\section{Bass as a SubJect for Experiments on Schooling.}

Choice of schooling fish suitable for observation in captivity is limited to a very few species. Small mackerel, herring, and sprat are excluded on account of difficulties involved in keeping them in confinement. The species most readily obtainable was the bass (Morone labrax), a fish which, though not such a specialist as the herring or mackerel, has quite a strong tendency to form schools.

The bass is a lively, vigorous fish with a traditional reputation for capriciousness and wariness. Admittedly, when all the facts known about its habits are considered, one cannot avoid the conclusion that its behaviour is normally far less stereotyped than that of most fish, showing much diversity and adaptability. Its diet, which is principally animal, preferably alive, covers a wide range from seaweeds to sewage effluents, and various are the methods adopted by the fish in obtaining it. The bass also shows considerable powers of resistance to environmental fluctuations such as changes in salinity and lack of oxygen. It lives well in captivity, surviving conditions that would be detrimental to most fish. In captivity it is seen to be alert and quick to take alarm-in fact, gives the appearance of living in a considerable state of nervous suspense-but is capable of becoming habituated to such conditions, if constantly repeated or continually present, as at first produced fright reactions.

The schooling habit is best developed in the younger fish which invade estuaries during summer months. At this period, especially in the earlier part of the season, while feeding vigorously, they form considerable schools, and even when the larger schools disperse the fish still keep together, at least in small parties. Schooling behaviour appears to weaken as the season advances. It has been observed (2, p. 117) that fish of the same size school together.

Summarily compared with other schooling fish, the bass may be said to represent a type in which schooling behaviour is not developed to such a predominating extent that it is practically stereotyped into automatic action, but rather, so to speak, exists as one of several forms of behaviour which at different times are liable to emerge from the general " behaviour pattern." In other words, it is a good generalised type in which schooling 
behaviour is present, but not in an exaggerated form. Compared with the schooling habit of specialists like the herring, that of the bass is not so well defined, nor so deeply engrained, nor so persistent. A variable element in seasonal change has been indicated above. Observations in captivity show that there is a considerable difference in the intensity of this behaviour under different circumstances, being stronger, for instance, when the fish are alarmed, and weaker when hungry. By the comparison of the behaviour of bass kept in an aquarium tank with that of grey mullet and mackerel under similar conditions and with sprat in tidal pools, it was seen that of these four species the orientation of individuals in relation to one another is least evident in the bass. In this species also there is much scope for independent individual action. In fact, when a number are together in a moderate sized tank, there is little, if any, evidence of schooling behaviour. Yet, as is shown below, individual fish have a strong attraction for each other.

It is this attraction between individuals that was made a basis for the experiments here described.

\section{DESCRIPTION OF EXPERIMENTS.}

\section{Preliminary.}

Preliminary investigations were started in October, 1929, on four fish, between 6 and 7 inches long, taken from the tank in the aquarium where a considerable number had been living for some months. They were placed in a tank in the main laboratory. A view of the interior of the tank $\left(58 \frac{1}{2}^{\prime \prime} \times 31^{\prime \prime}\right.$ and $18 \frac{1}{2}^{\prime \prime}$ deep, holding a depth of water of $\left.14^{\prime \prime}\right)$ was obtainable through the front which, except for the lower 6 in., consists of glass. The other walls of the tank are dark and the glass was covered with black paper, leaving only a space for a peephole in the middle. When not in use the peephole was kept covered over. Besides this, no attempt was made to exclude such disturbing influences of the surroundings as might be reflected in the behaviour of the fish.

The difference between the surroundings in the aquarium and those in the laboratory tank were considerable and it is not surprising that for some time the behaviour of the fish was dominated by "fear" or "response to disturbance " actions. At any rate, they were much inclined to keep to the far side of the tank, lying low in corners or behind a vertical outlet pipe in the centre. This, on the one hand, contrasts with the behaviour in the aquarium tank, in which the fish displayed considerable activity, swimming high in the water and attracted rather than repelled by movement outside the glass; and on the other hand is clearly related to behaviour towards a disturbance, from the side or above, when the fish, having at first darted rapidly to and fro, take up a position of rest low 
down in a corner or under some shelter if available, and lie quiet facing the source of disturbance.

As time went on the fish became less and less inclined to lie low at the back of the tank. Movement at the peephole had increasingly less effect. In fact, when the observer was quite still and took care that as little light as possible entered through the peephole, the fish behaved unconcernedly, so long as they did not swim up too close.

During observation on these four fish in daylight, with the aid of glass partitions set up in the tank, the following conclusions were soon reached.

(1) Fish placed in a tank, especially if disturbed, collect together and are restless when separated.

When their "attention was attracted" they bunched together orientated towards the source of disturbance. If one began to move away the others followed. But they also kept together when undisturbed. All through subsequent experiments when more than one fish was used the tendency was very evident.

(2) Fish separated by a glass partition move towards each other and school on either side of the glass.

The following tests were made :-

(a) Two glass plates (XY, YZ) were placed in the tank as indicated in Figure 1. The usual position of the fish (when the tank is clear) is along AB. When the plates were put in, one fish was separated from the other three which were penned in the area XYZ. When observation began the three inside fish were lying behind the vertical outlet pipe $(\mathrm{OP})$, while the single fish lay up against the glass at $\mathrm{X}$. The three fish moved in the direction of B ; whereupon the single fish made great efforts to follow them, persistently swimming up against the glass XY.

This was repeated on two other occasions with the same result.

The outside fish was observed attempting to pass XY when the other fish had come to rest near $Z$. The attraction of the one for three was always greater than that of the three for one.

A black plate, $\mathrm{PQ}$ (Fig. 2), was placed against XY so as to cover it for much of its length, leaving, however, QY free. Whereas (1) before this the fish had attempted to pass through region $\mathrm{XQ},(2)$ when the plate was put in it kept to region QY ; and (3) when the plate was shifted to $\mathrm{P}^{1} \mathrm{Q}^{1}$ it attempted to pass $\mathrm{XP}^{1}$.

(b) Three fish were penned by glass plates within area XZ (Fig. 3), one left outside.

Outside fish, previously, when entirely alone in the tank, was not observed to come forward at all from region $\mathrm{AB}$. 


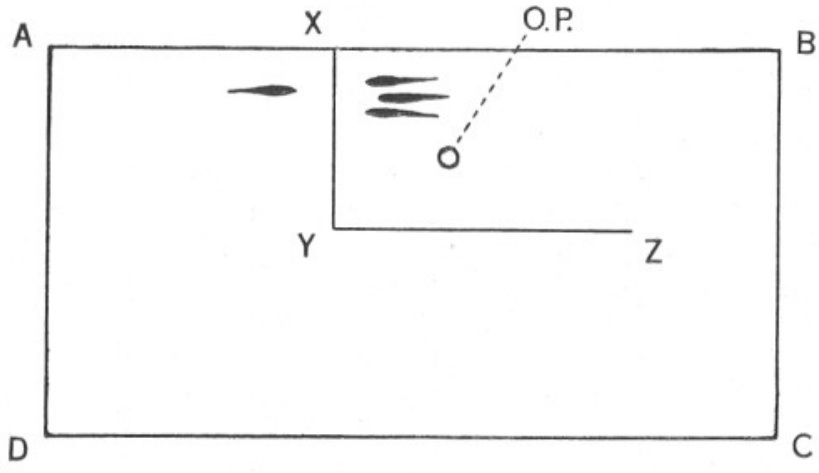

Fig. 1 .

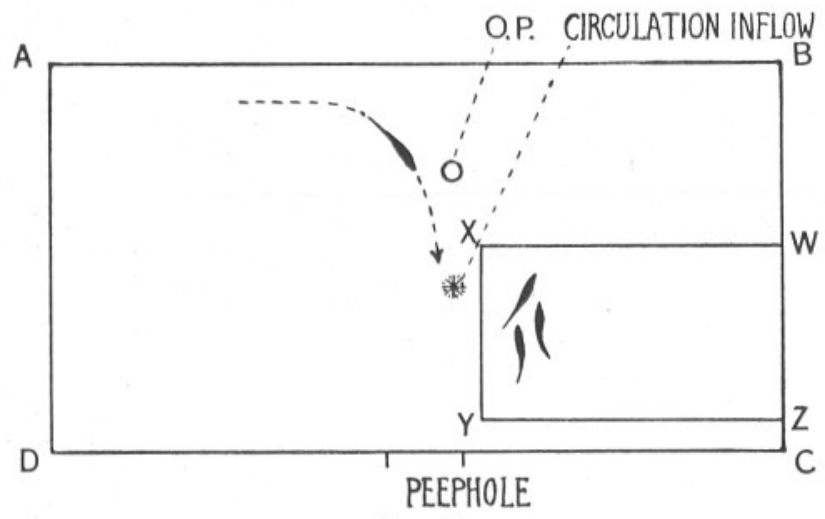

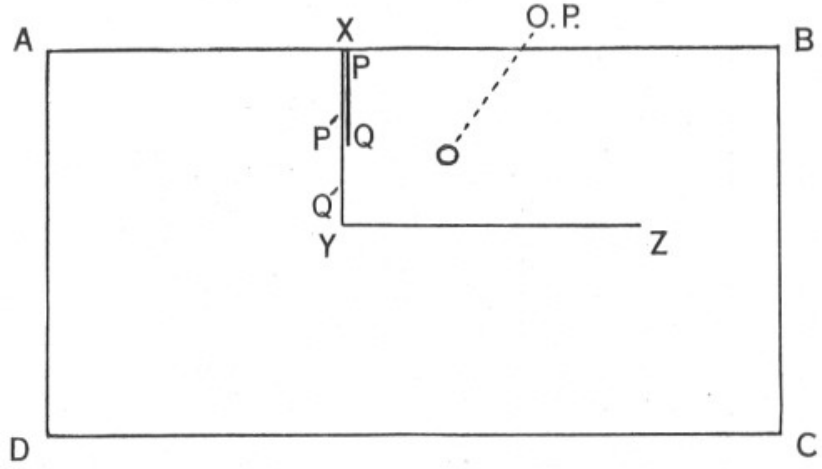

FIG. 2.

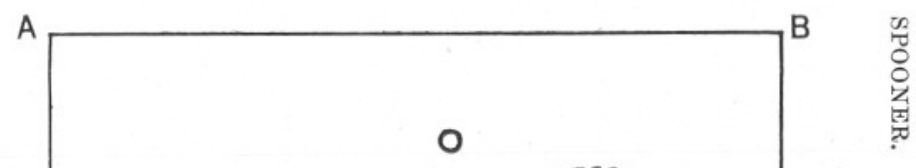

Fig. 3.

Figs. 1-4.-Diagrams of the arrangement within the tanks on particular occasions during the course of the experiments. (See text.) $\mathrm{ABCD}=$ Outlines of tank. W, X, Y, Z in all cases represent glass partitions standing vertically in the water. They were supported at their lower corners by bricks, which are not shown in the figures. O.P. = The overflow pipe standing vertically in the water. 
But when the three fish are in $\mathrm{XZ}$ the outside fish was seen on many occasions to swim forward towards the peephole along XY.

Note.-The outside fish came up more readily when the circulation inflow was striking the water at the point marked with a star, close to region of XY, and breaking the surface. On one occasion the observer was looking down from on top. When the circulation inflow was turned off or diverted into $\mathrm{XZ}$, so clearing the view, the fish did not come forward when the observer was looking down into the tank, but did so when the observer was keeping still at the peephole.

The outside fish now and again tried to pass into $\mathrm{XZ}$ between $\mathrm{X}$ and $\mathrm{Y}$, and in one case between $\mathrm{X}$ and $\mathrm{W}$.

Black plates were put in positions XP and XQ (Fig. 4). (i) The four fish took up position on either side of PY, thus indicating that the inside fish were affected by the other and not merely the other way round. (ii) Subsequently the inside fish took up various positions; the outside fish spent much time moving round arc MN, now and again attempting to join the inside fish either at QW or PY.

The black plates were tried in other positions, always with the same results; the outside fish attempted to pass through the clear glass spaces towards the inside fish.

All results were seen to be independent of the position of the circulation inflow-this did not appear to offer any attraction. It could be used with advantage as a screen.

(c) The tank was divided down the centre by a glass partition (Fig. 5). Normal position of fish somewhere along AB.

Two pairs of fish are separated by the glass.

If left alone they collect on either side of XY and orientate themselves, as a rule, in the same direction. They frequently are observed attempting to pass through the glass partition, and will snap at food falling on the other side of the glass.

If a black plate is placed at XY the fish take up a position at $\mathrm{P}$. If frightened back they come forward again in a short time, even though they may be moving towards a source of disturbance.

$\mathrm{XY}$ glass only . . . $\quad$ Fish greater part of time at XY.

$\mathrm{XY}$ glass + black plate . Fish for a larger part at $\mathrm{P}$.

However, two pairs of fish do not exert the same mutual attraction. as two single fish or as one fish towards three.

The mutual attraction that exists in these fish is best seen, then, in the case of a single fish separated off from a batch of others.

(3) The attraction of one fish for another may be strong enough to overcome what would otherwise be repelling effects. 

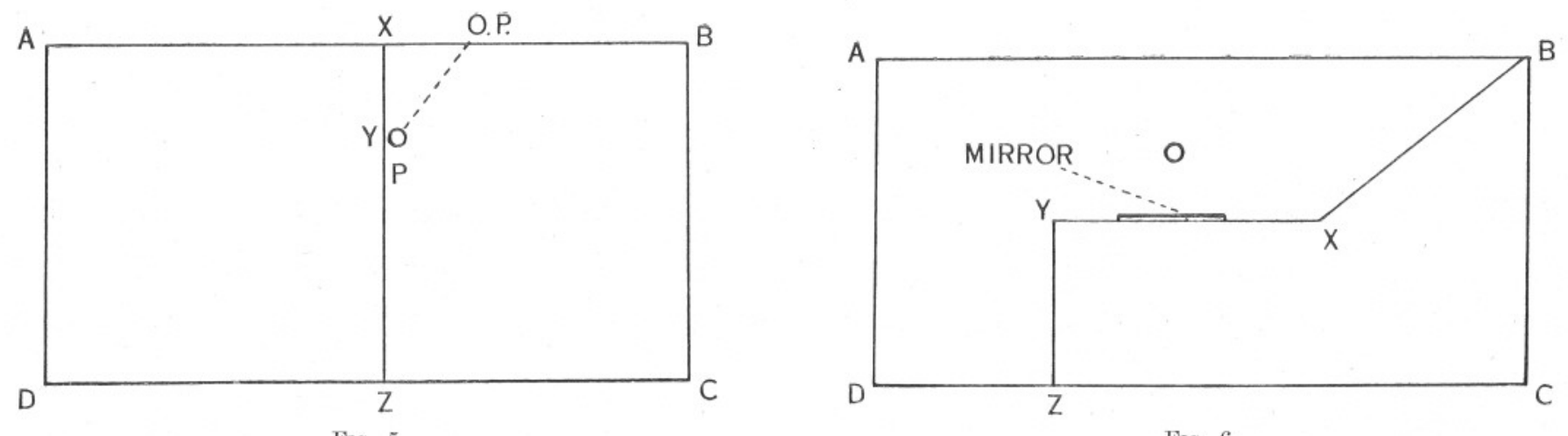

㬱
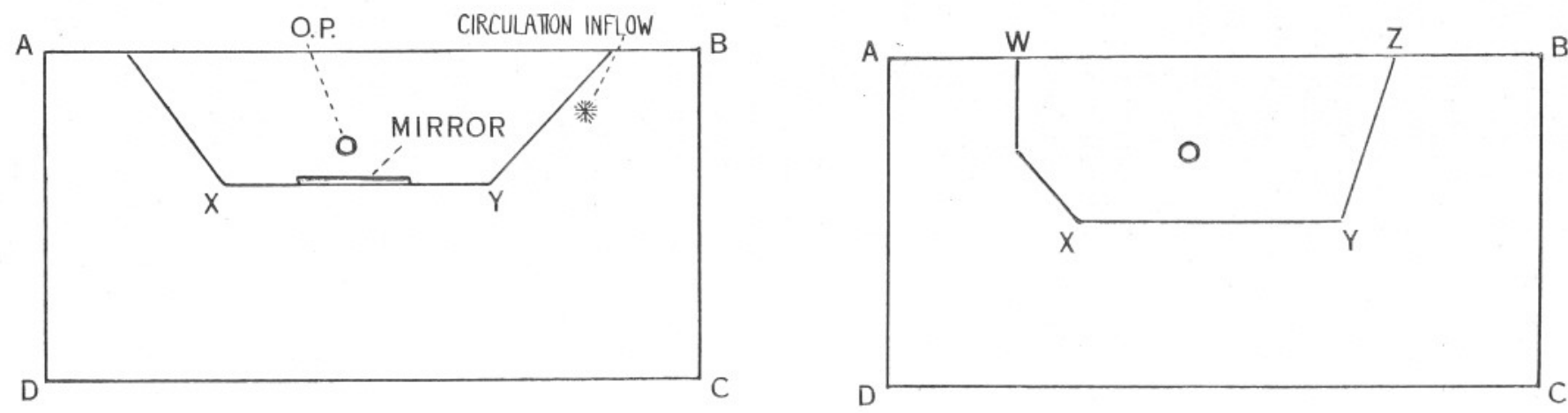

9

?

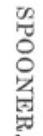

FIG. 7 .

Figs. 5-8.-For description, see Fig. 1, pages 427, 428.

Fig. 8. 
An instance of this has been given above. An isolated fish moves towards peephole when attracted by fish penned in glass.

In addition there was good indication that :-

(1) The fish do not readily, if at all, "sense" the glass plates. They will swim into them, and often persist for some time in swimming against them when held up.

(2) The fish behave as if reacting to each other by sight, the evidence being :-

(a) A fish separated from others by glass alone will make conspicuous eiforts to pass through towards other fish. But this does not happen if they are separated by an opaque screen, although enough space is left for the passage of dissolved substances or vibrations in the water.

(b) There is never any reaction to the spaces or crevices on the edge of the separating plates.

(c) When a fish is attempting to pass through a partition which is partly opaque and partly transparent, it will only attempt to pass through the transparent parts.

\section{Showing that Sight is Involved-Reactions of the Fish to A Mirror.}

In order to test out the proposition that bass react to each other by means of sight, experiments were carried out on the behaviour of the fish in the presence of a mirror.

From this point a second tank $\left(59^{\prime \prime} \times 30^{\prime \prime}\right.$, holding a depth of $15^{\prime \prime}$ of water $)$ was used, situated in a part of the laboratory where the light was dimmer and in general less liable to disturbing influences. In order that the fish might be observed without being disturbed at all, a hood of black cloth was hung over the side of the tank (in addition to black paper stuck on the glass), arranged over the peephole in such a way that all light from behind was cut off, and the observer's face rendered invisible.

The arrangement proved entirely satisfactory, its effectiveness being finally estimated by the influence, if any, on the behaviour of the fish. The fish frequently swam alongside the peephole showing not the least concern for any strange appearance that may have intruded upon their visual field. It was possible, however, if right up close to the glass, to produce by movement a reaction on the part of the fish.* It is beside the point to consider whether the fish detected the observer (whatever that means) or not; what matters is whether behaviour was affected or unaffected. And as in this case there was a clear contrast between

* For kind of movement, see below. 
"behaviour affected by movement at peephole" and "behaviour unaffected," it was possible to estimate when the latter condition held.

The reactions of the fish when coming in front of a mirror are best seen in single specimens isolated from the rest. If in a moderately active state, it spends a good deal of time swimming to and fro across the mirror surface with its face close against the glass as though attempting to pass through it. It passes up and down, often making futile snaps at the surface and displaying other reactions characteristic of frustrated effort. When the head passed beyond the field of the mirror, the fish very frequently pulled up short and turned back. This action, very striking on occasions, showed clearly that the abrupt change from a visual field containing the reflection to a visual field without it may provide a sufficient stimulus to produce a sharp reaction in the fish. Since precautions were taken to have the background approximately similar in the two fields, the difference between the two fields is reduced to that between presence and absence of image, and it is safe to infer that the sudden disappearance of the mirror image in the visual field of the fish is enough to stimulate a sudden reaction.

When the fish is in a less active state it lies up against the mirror for hours at a time. If driven off it will be back again before long.

Particular cases are described below. Small specimens of 3 and 4 inches reacted in a most energetic manner.

The behaviour thus outlined suggests that the mirror image exerts an influence identical with that of the presence of another individual, evoking a schooling response. Definite proof, however, that the image itself really counts for something was furnished during the course of various experiments. One particular instance is of itself practically conclusive.

Glass plates were arranged as shown in Figure $6(\mathrm{BXYZ})$. There is a single fish in the tank in front of the glass (area YC). Along XY is placed a mirror covered with black paper except for a rectangular patch of $1 \times 2 \frac{1}{2}$ ". During a period of two days the fish is observed to react to its reflection in the mirror exposure and to lie up against it for hours. After this a piece of plain glass similarly covered with black paper with a similar $1 \times 2 \frac{1}{2}^{\prime \prime}$ opening was substituted for the mirror. The fish did not react to the opening in at all the same way, but still rested in the region in front of it. The mirror was then replaced, this time along YZ. The fish just afterwards reacted to its reflection and remained in the region before YZ. Mirror and glass were then interchanged and the fish returned to its former position. The interchange of mirror and glass was repeated several times and in every case the distinction in the behaviour of the fish in front of the openings was most definite, the mirror being invariably " discovered." The effects of relative position being excluded by interchange of the plates, the only difference between the two rectangular openings in the black surface was that one contained a reflection of the fish and the other not. 
As might be expected, the mirror exerts less attraction on two or more fish together than on one isolated individual-progressively less as the number increases. Nevertheless the same sort of behaviour is seen and individual fish may for a time react quite intensely.

\section{Summary of Experiments with a Plain Mirror.*}

\section{A. Reactions of individual fish.}

1.

Eleven days after the original four fish had been placed in the first tank, they were presented with a rectangular mirror in a brown wooden frame. Being evidently "put off" by the unfamiliar appearance of the frame, none of them behaved in a way which gave much evidence of the effect of their mirror reflection. But when one of the fish (A) was moved to the second tank, the mirror being stood across one corner, a most definite reaction was seen. Since the whole situation was new for the fish, it might have been expected that the mirror and its frame would not exert the same repellent effect as when placed among already familiar surroundings. Again, whereas the fish had always been accustomed to the presence of others its own kind and size, it was now alone. Further, since it had been subjected to the shock of capture in a net and transference from the tank to another, its shoaling instinct should be strong.

It was found that in whatever part of the tank the mirror was placed, wherever the fish was driven, it always returned to the mirror after a short time. Now it swam over the surface, obliquely, with its head against the glass, as though trying to pass through to the other side of the frame; now around in the region close in front of the glass. When it passed out of the sphere of the mirror, it always turned back again, and so, even when most active, remained in one very restricted area. The turning back was most striking when the fish moved along the mirror's surface. On passing the frame (as it was constantly doing) it immediately turned back sharply and often moved in an agitated way until its reflection appeared before it once more.

When not active the fish lay alongside the mirror.

The mirror was placed in different parts of the tank; in every case the fish was attracted to it, behaving in the way described above.

This sort of behaviour has been found to be typical, though it may not always be so intense or so definite.

* These were carried out mostly in daylight, but sometimes in the evening under artificial light. The fish behaved in the same way in either case. 
2 .

Another fish was then placed in the tank with the above. The hood had now been fixed over the tank so that the fish could be observed without being distracted by the observer. On the first day the reaction was weak. On the second day it was quite strong: every time the fish were observed they were in the region of the mirror, either resting by it or moving slowly round in front of it. On passing beyond the view of their reflection they turned sharply back.

The next day the mirror was removed from its frame and used from now on as a simple rectangular plate $\left(10^{\prime \prime} \times 8^{\prime \prime}\right)$. The fish were immediately attracted to it and for the rest of the day their reaction was quite strong.

The mirror was then placed in the position shown in Figure 7, the region behind the vertical outlet pipe being cut off by glass partitions with mirror lying up against the longitudinal partition XY facing the peephole. The field of the mirror differed from that of the adjoining glass in that the reflected wall stood further back than the real back wall seen through the glass.

On the first two days the fish, whether active or not, showed quite a strong reaction to the mirror. When active they swum around in the region between mirror and peephole, constantly turning abruptly towards the mirror when the reflections disappeared from the field of view ; when inactive, they lay up against it. On one occasion one of the fish got inside the partition ; it was much attracted by the outside fish which was busy reacting, in turn, to its own reflection.

Two special cases which showed the effect of the mirror image may be mentioned. On one occasion a fish moving along the line from $\mathrm{C}$ to $\mathrm{D}$, on arriving opposite the mirror (about $14 \mathrm{in}$. away) turned at right angles so as to approach it. Another time one fish was lying against, and at an angle to, the mirror; the reflection of the other, moving in the opposite direction, came into view ; whereupon the former turned and orientated itself accordingly.

Some tests with different models were then made, after which the mirror was again used. It was placed an inch or two behind the glass partition. This was eight days after the fish had been put in the tank. The reaction to the mirror was now distinctly weak. The fish were at first moving about actively and paying a certain amount of attention to the mirror; but not greatly attracted to it. Occasionally they try to pass through the glass towards it. But they mostly lay quiet in the lefthand side of the tank, and returned there even if shifted toward the mirror.

The fish seemed to be developing a " depressed condition," so, as a test, the mirror was removed and another fish placed inside the glass enclosure. The original fish were not in the least attracted-hence the failure to react 
to the mirror was accompanied by failure to react to other fish. The mirror was replaced, but the fish gave no reaction. They were then removed.

3.

Two new fish, netted in the Tamar Estuary a week before, were tried with the mirror arranged in a similar manner as above, but now the glass partition was further forward, half-way between the front and back walls of the tank. This gave less contrast between the background of the mirror and that of the plain glass. (Fig. 8, mirror against centre of XY.)

During the two days these two fish were watched they were greatly attracted by the mirror, spending much time swimming slowly between it and the peephole and not straying from this area. They do not try to. pass through the mirror, nor are much inclined to lie beside it; but then they do not closely attract one another. The reaction of these two fish is good, being much like that of the fish mentioned above.

4.

The behaviour of two small fish ( $\mathrm{K}$ and $\mathrm{L}$ ) of $4 \mathrm{in}$. and one $(0)$ of $3 \mathrm{in}$. was observed on several occasions. At this size much greater activity is shown than by larger fish. The reaction to the mirror, though variable, was typically most vigorous.

On the first occasion on which the small 3-in. fish $(0)$ was observed in front of the mirror it was alone. The mirror was put in the tank at 3 p.m. At 3.15 the fish was busily swimming before the mirror, in a state of great. activity, darting to and fro in front of it and continually swimming at it as though to pass through it. On these latter occasions the dorsal fin was frequently raised, an action which is characteristic of impeded movement. Every few minutes the fish was observed and all the time, until the last observation at 5.50, it was still reacting to the mirror in an astonishingly persistent manner. The next day the tank was divided down the centre by a glass partition and a single 6 -in. fish placed on the right, the small fish and the mirror being on the left. In spite of such distraction as may have been provided by the larger fish, the small fish still continued reacting strongly to the mirror, and if it moved away very soon returned.

Each of the 4-in. fish, when tested separately, behaved in a similar way, remaining for a long period in front of the mirror. At times they lay still against the mirror, but for the most part they swam actively up and down and to and fro over the surface, frequently raising their dorsal fin in agitated effort to pass through, and returning whenever they happened to move out of the range of the mirror reflection.

Fishes $\mathrm{K}$ and $\mathrm{O}$ together reacted strongly in the same way.

Four days later the three fish were put together in a clear tank. The 
mirror was stood up against the vertical outlet pipe for half an hour, but during this period the fish paid little attention to it. They were not attracting each other to any extent and passing the edge of the mirror was not sufficient stimulation to make them turn back to their reflections. It was noticeable that, on swimming past the mirror, they almost invariably wheeled and swam round behind the outlet pipe. Again, when, immediately after, the mirror was stood across the space behind the outlet pipe facing the side walls, the fish spent little time in front of it.

In contrast to this, three days afterwards it was observed that the three fish together reacted readily to the mirror. At first the tank was clear ; it was then partly divided down the middle by a glass partition as in Figure 10, the mirror being placed against the right side wall. At first there was only one fish in the right half, but very soon afterwards all three were on the right in front of the mirror.

These last examples provide an illustration of how behaviour is apt to vary from one occasion to another.

As a rule, however, it may be said that the small 3- and 4-in. fish react in a very decided fashion.

5 .

Many further instances were obtained showing the attraction exerted by the mirror on individual fish. The behaviour exhibited by them was always essentially of the kind described above.

Tests were also made on a group of about twenty fish and the reactions of individuals were seen to be of the same definite character.

\section{6.}

In connection with the appreciation shown by the fish for their reflection, their behaviour with respect to reflecting surfaces lying on the floor of the tank has some bearing.

To a plain mirror reflecting light upwards the fish react in a most distinct and peculiar way. They swim over the glass, with the axis of the body tilted upwards (sometimes practically upright!) and snout close against the surface, in a rapid zigzag motion. They keep within the confines of the area of the mirror, turning inwards on reaching the edge.

To a piece of dark glass, lying on the floor of the tank or up against a sloping face of glass, they react in a like manner, but not so intensely. A distinct reflection is appreciable to the human eye.

To a piece of plain glass lying on the floor of the tank, a similar reaction is given, but it is far less decisive. There is still some sort of reflection in this case.

To a piece of plain glass tilted so that one end is raised and the other 
rests on the floor of the tank, there is no reaction. Reflection appears to be absent in this case.

To a piece of silver paper (which had previously been crumpled) lying under a piece of glass on the floor of the tank, there is even less reaction - when indeed there is any-than to plain glass alone.

The evidence of these facts indicates strongly that the mirror reflection is the essential element in the situation which evokes this characteristic behaviour. It is not merely the smoothness of the surface-a tilted piece of plain glass does not produce any reaction at all. The effect of dark glass shows that brightness is not essential, and of silver paper that brightness alone is ineffectual. Smoothness and brightness being thus eliminated, it must be concluded that the actual reflection of the fish, or some general characteristic of it, is concerned. The positive evidence for this is that the intensity of the fish's reaction decreases with decrease in clearness of the reflection.

7.

These, then, are examples of cases in which bass were observed to behave in a distinct manner when in the presence of a mirror. This behaviour is comparable in kind and intensity to that towards other fish behind a glass partition. This serves to show-even in the absence of other evidence-that in this species vision plays a leading rôle in schooling. The reflection calls out the same reactions as would real fish under similar circumstances. It "stimulates schooling reactions"; it creates a "schooling situation."

As far as the actions of individuals are concerned, they are nevertheless apt to vary in intensity from one occasion to another and are far from automatic. They vary even with the fish's activity. Indeed, on the whole, though the type of behaviour is characteristic enough, there is no definite cut-and-dried reaction which could be used as a basis for detailed experimentation.

\section{B. General power of attraction of a mirror as determined by comparison of average positions of the fish.}

1. Single fish.

For this test a fish was specially chosen which was hardly appreciably reacting to its reflection and which, to all appearances, was scarcely attracted to the mirror at all. An attempt was made to compare the frequency with which the fish was positioned in front of the mirror with that in front of a plain glass with similar background. The fish never lay for any length of time in front of the mirror; could it be shown that it was more frequently in front of the mirror than in front of a similar patch of plain glass?

NEW SERIES.-VOL. XVI. NO. 2. JUNE, 1931. 
The glass plates were arranged as in Figure 8 . The front 28 -in. plate was covered with black paper (kept in place with elastic bands) leaving two square openings, each $14 \times 13 \mathrm{~cm}$. A mirror is placed behind one of these and the other space left clear. The reflected background is very similar to the actual background seen through the clear space.

The frequencies of the occurrence of the fish in front of the two spaces are compared with one another. By this means an indication may be given as to whether the presence of the mirror makes any difference.

The fish is rather sluggishly disposed and shows little definite reaction to the mirror. Hence if any results are obtained from it, other fish should give more decisive results.

During the period this fish was being observed, a note was made every time it was seen in front of one of the spaces (irrespective of the reaction to it) or in the region between, and this was indicated in the accompanying table by $\mathrm{a}+$. The time is divided up into $\frac{1}{4}$-hour periods, in each of which no more than one + is available for any one column.

The results obtained were as follows :-

\begin{tabular}{|c|c|c|c|c|}
\hline & & $\begin{array}{l}\text { Plain } \\
\text { glass. }\end{array}$ & $\begin{array}{c}\text { Region } \\
\text { between. }\end{array}$ & Mirror. \\
\hline \multirow[t]{12}{*}{ 6.viii. 30} & $9-9.15$ a.m. & - & - & + \\
\hline & $9.15-9.30$ & - & + & + \\
\hline & $9.30-9.45$ & - & + & - \\
\hline & $9.45-10.0$ & - & - & - \\
\hline & 10.20 & - & - & - \\
\hline & 10.45 & - & - & - \\
\hline & 12.0-12.15 p.m. & - & + & + \\
\hline & $12.30-12.45$ & - & - & + \\
\hline & $12.45-1$ & - & - & - \\
\hline & $2.45-3$ & - & - & - \\
\hline & $5.45-6$ & - & - & + \\
\hline & $6-6.15$ & - & - & - \\
\hline \multirow[t]{10}{*}{ 7.viii.30 } & $9.45-10.0$ & - & - & + \\
\hline & $11.15-11.30$ & - & - & + \\
\hline & $12.0-12.15$ & - & - & - \\
\hline & 3.0 & - & - & - \\
\hline & \multicolumn{4}{|c|}{ (Mirrorchanged over) } \\
\hline & $3.45-4.0$ & + & - & + \\
\hline & $4.0-4.15$ & - & + & + \\
\hline & $4.15-4.30$ & - & - & - \\
\hline & 4.34 & - & - & - \\
\hline & 5.10 & - & - & - \\
\hline \multirow[t]{5}{*}{ 8.viii. 30} & $8.45-9.0$ & - & + & + \\
\hline & $9.15-9.30$ & - & - & + \\
\hline & $9.30-9.45$ & - & + & + \\
\hline & $10.15-10.30$ & - & + & + \\
\hline & $10.45-11.0$ & - & + & + \\
\hline
\end{tabular}




\begin{tabular}{|c|c|c|c|c|}
\hline & & $\begin{array}{l}\text { Plain } \\
\text { glass. }\end{array}$ & $\begin{array}{c}\text { Region } \\
\text { between. }\end{array}$ & Mirror. \\
\hline & $11.0-11.15$ & + & + & + \\
\hline & $11.15-11.30$ & - & + & - \\
\hline & $11.30-11.45$ & + & - & - \\
\hline & $11.45-12.0$ & + & + & - \\
\hline & $12.0-12.15$ & - & + & - \\
\hline & $12.15-12.30$ & _- & + & - \\
\hline & $12.30-12.45$ & - & + & - \\
\hline & $1.15-1.30$ & - & + & - \\
\hline & 8.30 p.m. & - & + & - \\
\hline & $8.45-9.0$ & - & + & + \\
\hline & $9.0-9.15$ & - & - & - \\
\hline 11.viii.30 & 9.30-9.45 a.m. & - & - & + \\
\hline & $11.15-11.30$ & - & - & - \\
\hline & $11.45-12.0$ & - & + & + \\
\hline & $12.45-1.0$ & - & - & - \\
\hline & $2.30-2.45$ & - & - & + \\
\hline & $3.0-3.15$ & - & - & + \\
\hline & $3.30-3.45$ & - & - & + \\
\hline & \multicolumn{4}{|c|}{ (Mirror changed over) } \\
\hline & $4.15-4.30$ & - & + & + \\
\hline & $5.0-5.15$ & - & - & + \\
\hline & $5.15-5.30$ & + & - & - \\
\hline & $5.30-5.45$ & - & - & + \\
\hline & $8.30-8.45$ p.m. & - & - & + \\
\hline & $9.0-9.15$ & - & - & + \\
\hline & $9.15-9.30$ & - & - & + \\
\hline & Total & 5 & 19 & 27 \\
\hline
\end{tabular}

The figures representing Mirror : Space between : Plain glass are $27: 19: 5$, showing a very decided balance in favour of "Mirror "-there is a greater probability that the fish will be in front of the mirror than in front of the plain glass.

\section{Aggregate of fish.}

With a number of fish in the tank an attempt was made to show that the presence of a mirror would affect their distribution, i.e. if the mirror were placed at one end there should be, on the average, more fish in that half of the tank than in the other.

For this purpose the tank was divided down the middle with a glass plate, leaving a gap just in front of the peephole (Fig. 10). The tank was that used in preliminary tests, with no hood or any special precautions for rendering the observer invisible.

There were 21 fish of between 6 and $7 \frac{1}{2}$ in. in the tank. They moved about the tank on the whole quite actively, and when left to themselves soon equalised their numbers in the two halves. At intervals the numbers in the two sides were counted, observation being made through the 
peephole. Owing to the observer's presence, the fish would no longer swim to and fro in the connecting space; so the numbers in either part of the tank could be counted at leisure. For the most part it was sufficient to count the fish in that part of the tank in which there were least.

The distribution of this group of fish in the two halves of the tank is represented graphically. Figure $11(a$ and $b)$ shows normal condition, the

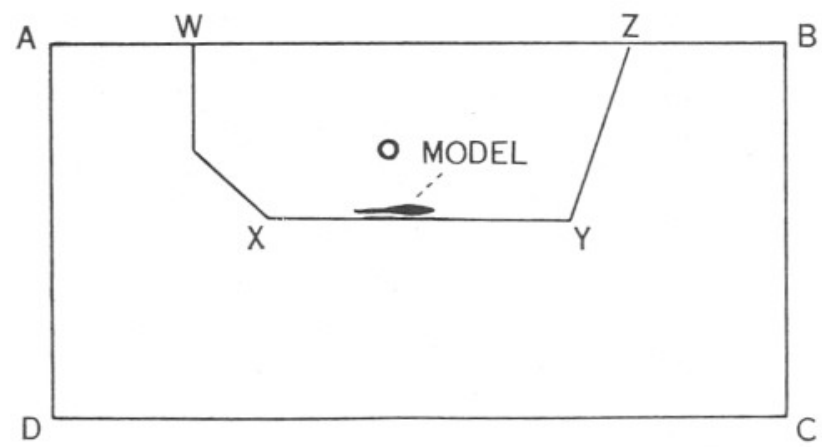

FIG. 9.

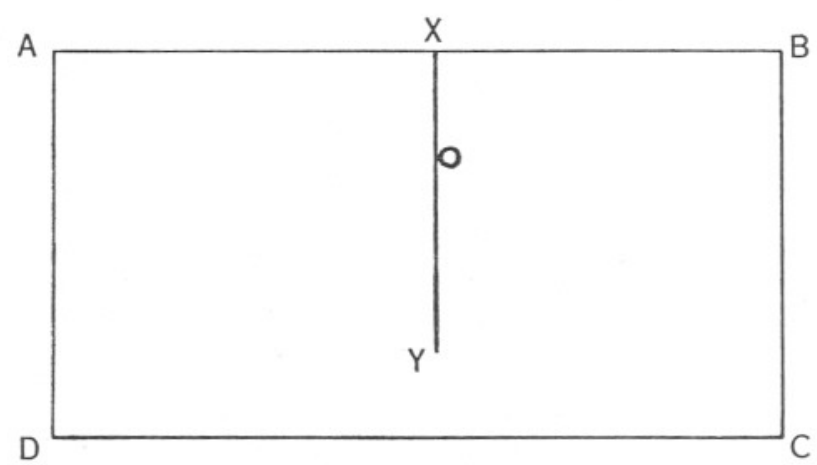

Fig. 10.

Figs. 9-10.-For description, see Fig. 1, pages 427, 428.

fish being distributed with equal probability of preponderance in either half. Figure $12(a$ and $b)$ shows the effect of a mirror standing up against one of the side walls.

There is a clear distinction between the two cases. The results show : (a) the probability of a larger proportion of fish in that half of the tank which contains the mirror; $(b)$ the marked change in distribution following the change of the mirror from one side to the other. 


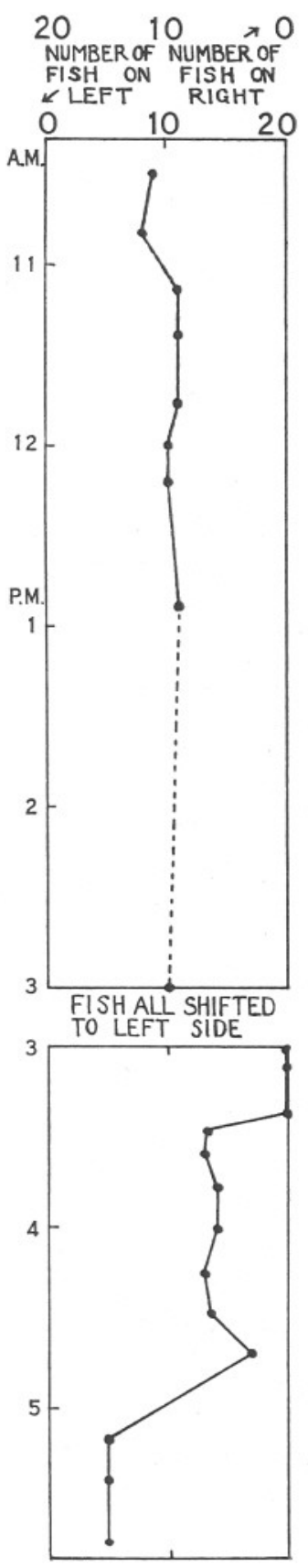

a.

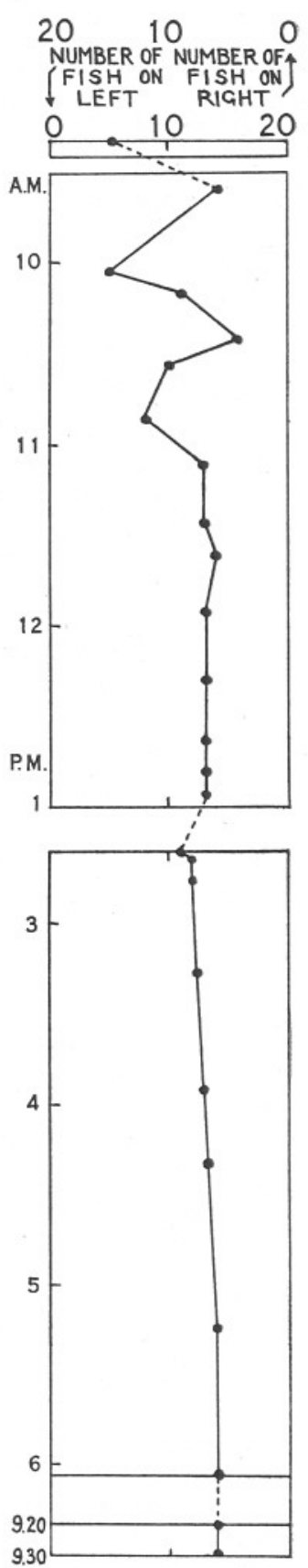

$b$.

FIG. 11.-Graphs showing the distribution of a party of 20 or 21 fish in the two halves of a tank arranged as in Fig. 10. Two examples of the normal type of distribution. 
The Main Attributes of That which induces a Schooling Response.

A bass is attracted towards another of its kind separated by a glass partition; it is attracted by its own reflection in a mirror. It may be asked, what are the essential characters in the object of attraction as

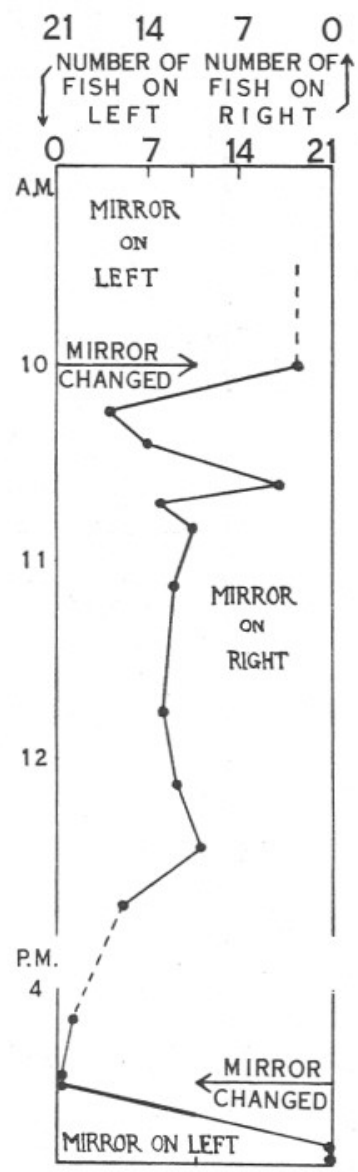

a.

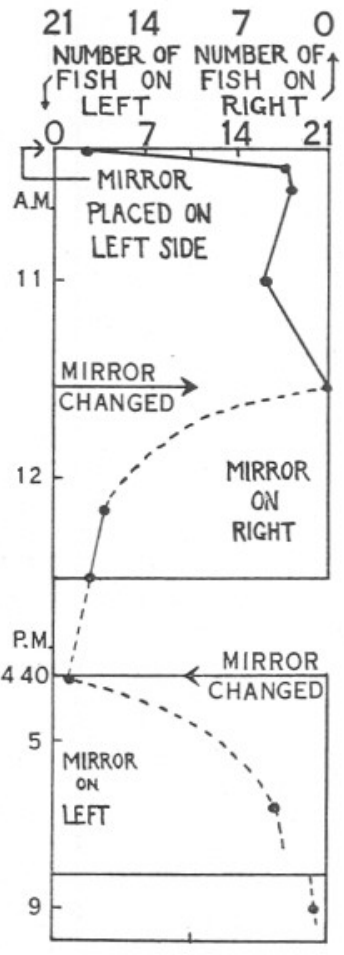

$b$.

FIG. 12.-Graphs showing the distribution of a party of 20 or 21 fish in the two halves of a tank arranged as in Fig. 10. The effect of placing a mirror on one side and periodically changing it.

distinguished by the fish ? Even granted that it is the " general appearance" as a whole which is significant, it may still be asked what are the main elements which contribute to the general resemblance-whether form, or movement, or pattern. 
It was found that the fish will be attracted to, and lie alongside, a dead fish supported by glass in the position of a resting live fish.

The tank was fitted as shown in Figure 9. Two fish were in front of the glass. A dead fish supported in a glass jar was placed in the position ("MODEL") previously occupied by a mirror to which the fish had reacted well. (The tank was subjected to considerable disturbance while the arrangement was being fitted up.)

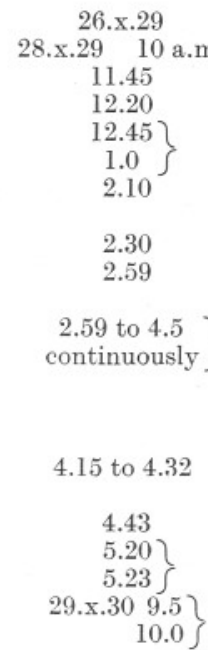

10.10

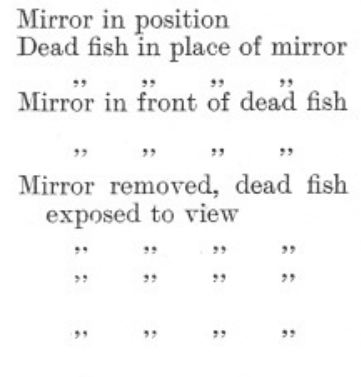

Fish in region before mirror.

Fish quiet in region of CD ? Interval

" " , " $\quad$ effects of

Fish not in front of mirror $\begin{gathered}\text { disturbance } \\ \text { wore off. }\end{gathered}$

Both fish by mirror, but disturbed by the removal of it.

Fish in region of CD, not by dead fish.

Both fish lying up against dead fish, all facing in the same direction.

All this time the fish were lying up against dead fish, quiet.

Sometimes orientated in some direction, sometimes in opposite, sometimes both differently.

Fish away from dead fish in L. centre of the tank.

At least one fish by dead fish.

Both fish lying by dead fish.

Through this period the fish were lying against dead fish, all orientated in the same direction.

On another occasion a similar experiment was repeated with similar results.

This shows clearly enough that the fish are attracted by the form of another fish, although it is completely devoid of movement. Hence movement of fins, for instance, is not an essential item.

Following on the experiment outlined above, several kinds of rough models were tried. One type bore the exact shape of the fish and was painted green, another of plasticene with a roughened surface, another a piece of bent tinfoil shaded dark in the upper half. The fish were attracted by none ; when they were too conspicuous the fish were definitely repelled. And it is scarcely surprising, for however much the models resembled fish in the air, under the water they stood out all too crudely. Little success was attained in getting a uniform lighting and still less in avoiding a harsh contrast with the background.

Still, it is at least an indication that the fish require an object that closely resembles a fish, the general shading and contrast between it and the background being important. 


\section{Reaction to Mirrors used as a Basis for further EXPERIMENTS.}

The fact that a fish will react, in a manner indicated above, towards other fish like itself might provide a starting-point for experiments to determine how far variation in the properties of the object to which reaction is made affects the results. For instance, what is the effect of cutting down the size of the space through which the object-whether another fish or mirror reflection-is viewed? How much of the fish or image is necessary?

Unfortunately the reactions of the fish to each other and to a mirror are not sufficiently cut-and-dried to provide a basis on which accurate comparisons can be drawn. It has been seen that the reaction of an individual fish to a plain mirror may vary considerably. For any given fish it is impossible to predict definitely how it will behave, but it is possible to say how it will most probably behave or the probable intensity of its reaction, especially if its condition is not abnormal. But it is not possible to measure this probability. Hence, in comparing the behaviour of an individual fish to a less efficient mirror or a less complete image, the comparison cannot be expressed at all accurately. All that can be said is that "the reaction on the whole appears less intense in this case than that " or " the probability for a certain reaction appears less in this case than that."

The nearest approach to a definite form of behaviour is seen in the case of a single fish in the presence of a mirror. It is strongly attracted to the mirror and spends much time in front of it. It is possible, therefore, to compare, as is attempted below, the behaviour of the fish towards various sizes of mirror exposure or various types of broken surface. But allowance must be made for greater variation in behaviour to less definite* situations

The method whereby the distribution of a number of fish gives statistical comparison (see pp. 441 and 442) does not lend itself for more refined application. It is adequate for showing the difference between " mirror " and " no mirror," but a glance at the figures is enough to show what little scope there is for expressing finer distinctions.

One attempt was made with the mirror covered over with black paper except for a slit $\frac{1}{2}^{\prime \prime} \times 10^{\prime \prime}$. This had no effect on the grouping of the fish.

Consideration of such a statistical method shows that, even if the school is large enough (which it isn't) to eliminate individual variations, there is no reason why the mean value of the "state" of the fish should remain a normal constant. If the "state" of one fish changes, it is very likely that other fish for the same reasons will be changing in the same way. Hence the mean value, as it were, will shift. It must also be remembered that

* i.e. situations in which there is less contrast. 
reaction to a mirror belongs to those set of reactions which keep the school together. Hence both reactions will interfere with each other; particularly will the presence of other fish decrease intensity of reaction to the mirror.

\section{Reaction of fish to small areas of mirror.}

With a view to obtaining evidence on how complete an image is necessary to bring out the kind of behaviour described in earlier paragraphs, the fish were presented with exposures of mirror of various sizes. These were obtained by covering over a mirror with black paper out of which a piece of the required dimensions had been cut. The reflections of the fish, therefore, came to view as though through a gap in a black upright partition.

The results of observations are summarised as follows :-

\begin{tabular}{|c|c|c|c|c|}
\hline & Whole & $\begin{array}{l}\text { Section } \\
\text { in } \times 10 \mathrm{in}\end{array}$ & Whole & $\begin{array}{c}\text { Section } \\
1 \text { in } \times 10 \mathrm{in}\end{array}$ \\
\hline Small fish & Reacted & One fish reacts strongly, & Reacted & No reaction at all: apart \\
\hline $\mathrm{K}, \mathrm{L}, \& \mathrm{O}$ & well. & $\begin{array}{l}\text { but is more attracted by } \\
\text { the other fish. }\end{array}$ & well. & $\begin{array}{l}\text { from certain slight } \\
\text { changes in their actions } \\
\text { which might be the } \\
\text { result of having de- } \\
\text { tected movement. }\end{array}$ \\
\hline
\end{tabular}

$\frac{1}{2}$ in. $\times 10$ in.

Various individuals have been observed to react to this slit, but has no statistical effect on a group of fish.

Fish M Small fish in tank Alone.

61 in. as well. Reacted fairly well

Reacted to reflection, but more attracted by young fish.

$$
1 \text { in } \times 10 \text { in. } \quad 1 \text { in. } \times 2 \frac{1}{2} \text { in. }
$$

Reacted as to Reacted very well. full mirror. A good contrast in behaviour towards a similar exposure of plain glass.

1 in. $\times 1$ in. Exposure.

Fish N Though watched over several days, about 6 in. never reacted at all.

As far as these tests go, it is clear that a complete image is not necessary, but it seems that it must be nearly complete. An eye alone or the head alone appears to exert no attraction. Furthermore, it must be remembered that the measure of the size of the exposure is no measure of the dimension of the image: when the eye is close to the aperture the field of view is extensive.

\section{Reactions to a broken mirror surface.}

One or two observations were made on the reactions of individual fish to a broken area of mirror surface. The mirror was covered with elastic bands, $\frac{1}{4}$ in. wide, spaced at definite intervals, running both across and along the surface. This gave a meshwork with small sections of mirror showing in between. 
The following results were obtained from three small active fish (K, $\mathrm{L}$, and $\mathrm{O}$ ) which reacted well to a full mirror.

Bands $\frac{3}{4}$ in. apart. Bands $\frac{3}{8}$ in. apart.

3 small fish, Definite reaction and Some sort of reaction $\mathrm{K}, \mathrm{L}, \& \mathrm{O}$. fish spent some time lying against it. but it was weak. Not attracted.
Bands $\frac{1}{4}$ in. apart. Scarcely reacted. Not attracted.

Another test showed that a number of fish will group in front of a mirror with a $\frac{3}{4}$-in. meshwork in the same way as in front of a partition of plain glass with similar meshwork through which other fish are visible beyond.

Experiments with banded mirrors were not continued because it became obvious that the results obtainable, unless possibly continued for an inordinately long time, were vague and of little value. When the bands were $\frac{1}{4}$-in. apart it could be seen that the fish on passing exhibited slight changes in their behaviour actions, and since bass are very sensitive to movement in the visual field it is not unreasonable to suppose that the movement of their reflection had effect on them. Movements of this kind are apt to attract the fish, no doubt because they are associated with "food situation." At what point is one entitled to distinguish between this type of attraction and that which produces a schooling response? One must pay attention to those reactions which are different in the two situations, i.e. in one case there is the tendency to remain near or lie still against the source of attraction, in the other case there is none. When the whole reaction becomes so indefinite that these actions do not appear for certain, distinctions can no longer be drawn.

\section{APPLICATION OF RESULTS TO THE SCHOOLING PROBLEM.}

We have now to consider in what respects the data so far obtained bear on the problem of school formation for the particular case of the bass, and may therefore summarise them under the headings set down in the introduction (p. 423).

$1(a)$. With the bass, we have not been concerned with maintenance of school formation by a party of active fish moving from place to place. Within the confines of a laboratory tank schooling phenomena were limited to the grouping together of the few individuals under observation, particularly when in a resting or not very active state. The actions of individuals, however, which bring about the grouping in a tank, are at least connected, if not identical, with those which concern school formation under natural conditions.

The following are the kinds of actions which were observed. Movement towards other individuals (or one individual) up to within a certain short distance; movement towards and stopping close besides resting 
individuals; the pursuit of another individual on the move ; orientation in the same direction as other individuals, either moving or resting; change of direction of movement following change in the course of another fish ; movement instigated at the appearance of a moving fish ; speed of movement adjusted to that of other fish.

(b) The aspect of the environment concerned in these actions involves some kind of visual image in which undoubtedly shading, shape, and other spatial relations are distinguished. For evoking schooling behaviour movement is not essential, and a complete image is not essential.

(c) Results are sufficient to show that sight is the predominant, if not the only, sense involved; but no experiments in sense physiology have been made to find what visual distinctions are most appreciated or what degree of refinement is exhibited.

2. It has been seen how bass in a tank are prone to group together, and, if separated, to move towards each other.

(a) They group more readily when disturbed or alarmed, and least when hunting for food. Small 3- and 4-in. fish will group with larger 6-7-in. fish, but not the larger with the smaller.

(b) The behaviour is variable, particularly in intensity, and cannot be profitably expressed on the basis of a simple tropism or system of tropisms. Since it clearly varies with the state of the fish, prediction of readiness to school cannot be made unless the state of the fish can be described.

(c) Two fish placed in a tank by themselves will keep fairly well together, but, if moving about actively, or engaged in feeding, or when signs of depression set in, their movements may be all but independent of each other. Inducing schooling experimentally goes no further than placing a fish which has a natural tendency to school under just those conditions which are normally required for schooling behaviour!

My best thanks are due to Dr. E. J. Allen particularly for suggesting this line of work and for the readiness with which he has given his valuable help and advice during the course of it.

\section{SUMMARY.}

1. Among schooling fish, the younger stages of the bass (Morone labrax) provide an instance in which the schooling habit, though strong, is not stereotyped into fixed forms of behaviour.

2. Observations were made on individual fish in connection with their attraction for one another, a special point being made of observing their behaviour in front of a mirror.

3. The data so obtained are summarised in the light of their bearing on the problems of school formation. 


\section{REFERENCES.}

1. Bateson, W. 1890. The Sense Organs and Perceptions of Fishes. Journ. Mar. Biol. Ass., N.S., Vol. I.

2. Aflalo, F. G. 1904. British Salt-Water Fish. Woburn Library.

3. PARr, A. E. 1929. A contribution to the theoretical analysis of the schooling behaviour of fishes. Bingham Oceanographical Coll. Occasional Papers. I. 